ORIGINAL ARTICLE

\title{
Effect of rifaximin in the prevention of acute kidney injury and hepatorenal syndrome type II in Egyptian HCV cirrhotic patients.
}

1) Ahmed Mohamed El-Gebaly, Tropical Medicine Department, Faculty of Medicine, Zagazig University, Egypt,

2) Nermin Saad Ghanem, Internal Medicine Department, Faculty of Medicine, Zagazig

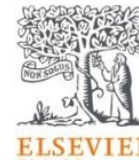
University, Egypt,

3) Ahmed Attia Abdelmoaty, Tropical Medicine Department, Faculty of Medicine, Zagazig University, Egypt,

Corresponding author: Ahmed Mohamed ElGebaly, Tropical Medicine Department, Faculty of Medicine, Zagazig University, Egypt. icegebo2011@yahoo.com

Submit Date 2021-01-13 Revise Date 2021-01-26 Accept Date 2021-02-23

\section{ABSTRACT}

$\mathbf{R}$ enal dysfunction as acute kidney injury (AKI) and hepatorenal syndrome (HRS) type II found in $20 \%$ of cirrhotic patients. HRS type II was identified by elevation of serum creatinine more than $1.5 \mathrm{mg} / \mathrm{dl}$, without improvement in serum creatinine after at least 2 days with withdrawal of diuretic and volume expansion with fluids or albumin. HRS type II is accompanied by hypotension and dilutional hyponatremia. The mechanism

\section{ABSTRACT}

Background: Hepatorenal syndrome type II and acute kidney injury found in $20 \%$ of cirrhotic patients. Rifaximin was found to reduce the frequency of hepatorenal syndrome type II and acute kidney injury in alcohol cirrhotic patients. This study aimed to evaluate the efficacy of rifaximin in prevention of hepatorenal syndrome type II and acute kidney injury in Egyptian HCV cirrhotic patients.

Methods: The study included 120 patients with decompensated post HCV cirrhosis selected from patients admitted to Tropical Medicine department and intensive care unit and from patients admitted to Internal Medicine department and intensive care unit. They were classified into two groups the first was a control group $(n=60)$ and the second was the rifaximin group $(n=60)$. Rifaximin group patients were administered rifaximin tablet $550 \mathrm{mg}$ twice daily for 12 weeks. All patients were revaluated every 4 weeks and followed up for 12 weeks in Tropical Medicine outpatient clinic and Internal Medicine outpatient clinic.

Results: The incidence rate ratio of acute kidney injury (IRR 0.7 [95\% CI 0.53-0.92]) and hepatorenal syndrome type II (IRR 0.21 [95 \% CI 0.06-0.70]) was statistically lower in the rifaximin group than the control group. The estimated mean change in the control group was higher than the rifaximin group in blood urea nitrogen [18.93(17.34-20.52) vs. 16.145(13.09-19.2) $\mathrm{mg} / \mathrm{dl} ; \quad \mathrm{P}=0.029]$ and serum creatinine $[1.0525(0.9425-1.1625)$ vs. $0.995(0.885-1.105) \mathrm{mg} / \mathrm{dl} ; \mathrm{P}=0.038]$.

Conclusion: Use of rifaximin is associated with decreased incidence of hepatorenal syndrome type II and acute kidney injury in Egyptian HCV cirrhotic patients.

Keywords: Rifaximin, hepatorenal syndrome type II, acute kidney injury, cirrhosis.

of HRS type II may result from spontaneous bacterial peritonitis (SBP) through translocation of bacteria, systemic and splanchnic arterial vasodilatation, altered renal physiologic autoregulation, adrenal insufficiency, and cardiac dysfunction [1]. AKI was defined as an increase in serum creatinine by $0.3 \mathrm{mg} / \mathrm{dl}$ within 48 hours or increase in serum creatinine to $>\mathbf{1 . 5}$ times baseline, which is known or presumed to 
have occurred within the prior 7 days; or urine volume $<0.5 \mathrm{ml} / \mathbf{k g} / \mathrm{h}$ for 6 hours [2].

Rifaximin is an oral antibiotic that poorly absorbed from the gastrointestinal tract. It has broad-spectrum in vitro activity with a low risk of developing bacterial resistance [3]. It is a potent drug in the prophylaxis and treatment of hepatic encephalopathy [4], which has been the center point of its research. Overgrowth of bacteria in cirrhotic patients is accompanied by increased levels of endotoxins and cytokines as interleukin-6 (IL6 ) and tumor necrosis factor- $\alpha$ (TNF- $\alpha$ ) which is accompanied by decreased systemic vascular resistance and increased risk of developing renal injury and death [13]. Rifaximin decreased circulating levels of TNF-a and enhanced hemodynamic by an increase in systemic vascular resistance and glomerular filtration rate and decrease in portal vascular resistance [4]. Studies on alcohol cirrhotic patients, rifaximin reduced the frequency of HRS type II and AKI [5]. This study aimed to determine the efficacy and outcomes of rifaximin in prevention of hepatorenal syndrome type II and acute kidney injury in Egyptian $\mathrm{HCV}$ cirrhotic patients.

\section{METHODS}

Informed consent and ethics committee/IRB approval:

The study protocol was approved from the Institutional Research Board committee at Faculty of Medicine, Zagazig University. The study was conducted according to the clinical practice guidelines and according to the Code of Ethics of the World Medical Association (Declaration of Helsinki) for studies involving humans. A written informed consent was obtained from every patient.

Study design:

A hospital-based non-interventional clinical trial was carried out in the Tropical Medicine department and intensive care unit and Internal Medicine department and intensive care unit Zagazig University, in the period from February 2019 and October 2020. All official permissions were obtained from the managers of the Tropical Medicine department, Zagazig University. The objectives of this study were explained to them to ensure their cooperation.

Patients' selection and data collection:

The sample size was calculated according to the expected positive predictive value of 70 , power of the study $85 \%$, and $95 \%$ confidence interval using EPI info 6. It included 120 Egyptian patients with decompensated HCV cirrhosis which was diagnosed by HCVab and polymerase chain reaction (PCR). They were selected from patients admitted to Tropical Medicine department and intensive care unit and also from patients admitted to Internal Medicine department and intensive care unit. They were classified into two groups. The first group was a control group (60) and the second group was the rifaximin group (60). The exclusion criteria were patients younger than 18 years old, patients who refused to give consent, patients with hepatocellular carcinoma or cholangiocarcinoma, patients with nephropathy, or on nephrotoxic drugs or patients with HRS type II. Patients with SBP must be excluded by ascitic fluid analysis. Sepsis had to be excluded (chest x-ray to exclude chest infection and pneumonia, complete blood count (CBC) to exclude any systemic infection and urine examination to exclude urinary tract infection and any renal abnormality such as proteinuria or casts). Rifaximin group patients were administered a rifaximin tablet $550 \mathrm{mg}$ twice daily for 12 weeks. On admission all patients underwent thorough full history, full clinical examination, $\mathrm{CBC}$, liver function tests, kidney function tests, INR, sodium, potassium, ascitic fluid analysis for exclusion of other causes of ascites and spontaneous bacterial peritonitis and pelviabdominal ultrasound. Patients were followed up for 12 weeks in Tropical Medicine outpatient clinic and Internal Medicine outpatient clinic. Every 4 weeks renal functions, CBC, LFTs, pelviabdominal ultrasound and diagnostic paracentesis were done. Patients were monitored for HRS type II and AKI. HRS type II was diagnosed by serum creatinine more than $1.5 \mathrm{mg} / \mathrm{dl}$, without improvement in serum creatinine after at least 2 days with withdrawal of diuretic and volume expansion with fluids or albumin. AKI was defined as an 
increase in serum creatinine by $0.3 \mathrm{mg} / \mathrm{dl}$ within 48 hours increase in serum creatinine to $>1.5$ times baseline, which is known or presumed to have occurred within the prior 7 days; or urine volume $<0.5 \mathrm{ml} / \mathrm{kg} / \mathrm{h}$ for 6 hours.

Data analysis

Data were analyzed statistically using IBM SPSS Statistics, version 21 for Windows (IBM Corporation, North Castle Drive, Armonk, New York, USA). Data are expressed as mean \pm SD. All $\mathrm{P}$ values are twotailed, with values less than 0.05 considered statistically significant. Comparisons between two groups were performed using Student's ttest for parametric data and the MannWhitney test for nonparametric data. $\chi^{2}$ and Fisher's exact test was used for categorical data analysis. Repeated-measures analysis of variance test was used for serial variables. Frequency is expressed as an incidence rate ratio (IRR) with $95 \%$ confidence interval (95 $\% \mathrm{CI}$ ) and was calculated using a Poisson regression model. A p-value $<0.05$ was considered statistically significant.

\section{RESULTS}

Table 1 exhibits the baseline data. There are no significant differences regarding age, sex, virology, liver function tests, INR, Child score, and potassium. Patients in the control group have a statistically significantly lower serum sodium level $(130.82 \pm 3.1$ vs. $132.9 \pm 2.9 \mathrm{mmol} / \mathrm{l} ; \mathrm{P}=0.04)$.

Table 2 exhibits the effect of rifaximin on the incidence rate of multiple variables. Thirtyseven patients in the control group had a total of 73 AKI episodes during the follow-up period, while 31 patients in the rifaximin group had a total of 61 AKI episodes. Thirteen patients in the control group had a total of 14 HRS type II episodes, while 3 patients in the rifaximin group had a total of 3 HRS type II episodes. The incidence rate ratios of HRS type II (IRR 0.21 [95\% CI 0.06-0.70]) and AKI (IRR 0.7 [95 \% CI 0.530.92]) are statistically lower in the rifaximin group than the control group, there is a high statistically significant difference between the groups regarding HRS type II and AKI. 26 patients in the control group developed (SBP), while only two patient in the rifaximin group developed (SBP) with highly significant difference.

Table 3 exhibits the impact of rifaximin on the serial renal functions (weeks 0 through 12). There is a statistically significant difference in the serial blood urea nitrogen (BUN) readings in the control group $(16.9 \pm 5.3,16.7 \pm 8.2,19.2 \pm 6.8$ and $22.92 \pm 6.3$ $\mathrm{mg} / \mathrm{dl} ; \mathrm{P}=0.008)$ in contrast to the rifaximin group $(14.8 \pm 5.4,16.6 \pm 5.4,17.8 \pm 4.2$ and $15.38 \pm 4.6 \mathrm{mg} / \mathrm{dl} ; \mathrm{P}=0.169)$. The $\mathrm{BUN}$ values are statistically higher in the control group than the rifaximin group in week 4 $(16.7 \pm 8.2$ vs. $16.6 \pm 5.4 \mathrm{mg} / \mathrm{dl})$, week 8 $(19.2 \pm 6.8 \mathrm{vs}$. $17.8 \pm 4.2 \mathrm{mg} / \mathrm{dl})$, and week 12 $(22.92 \pm 6.3$ vs. $15.38 \pm 4.6 \mathrm{mg} / \mathrm{dl})$. There is a statistically significant difference in the serial serum creatinine readings in the control group $(0.88 \pm 0.26, \quad 0.98 \pm 0.27, \quad 1.16 \pm 0.12$ and $1.19 \pm 0.2 \mathrm{mg} / \mathrm{dl} ; \mathrm{P}=0.006)$ in contrast to the rifaximin group $(0.96 \pm 0.17,0.95 \pm 0.25$, $1.08 \pm 0.11$ and $0.99 \pm 0.18 \mathrm{mg} / \mathrm{dl} ; \mathrm{P}=0.139$ ). The serum creatinine values are statistically higher in the control group than the rifaximin group in week $4(0.98 \pm 0.27$ vs. $0.95 \pm 0.25$ $\mathrm{mg} / \mathrm{dl})$, and week $12(1.19 \pm 0.2$ vs. $0.99 \pm 0.18$ $\mathrm{mg} / \mathrm{dl}$ ). The estimated mean change in the control group is higher than the rifaximin group in BUN [18.93(17.34-20.52) vs. 16.145(13.09-19.2) $\mathrm{mg} / \mathrm{dl} ; \quad \mathrm{P}=0.029]$ and serum creatinine $[1.0525(0.9425-1.1625)$ vs. $0.995(0.885-1.105) \quad \mathrm{mg} / \mathrm{dl} ; \quad \mathrm{P}=0.038]$, reinforcing the potential preventive effect of rifaximin in renal insult. 
Table (1) Baseline data for both groups:

Control group (60) Rifaximin group (60) P value

\begin{tabular}{lccc}
\hline Age $($ Mean \pm SD) $($ years $)$ & $56.3 \pm 8.2$ & $58.5 \pm 4.8$ & 0.18 \\
\hline Sex & $33(55 \%)$ & $36(60 \%)$ & 0.39 \\
- Fe male $\quad$ - Male & $27(45 \%)$ & $24(40 \%)$ &
\end{tabular}

\begin{tabular}{llll}
\hline Bilirubin $(\mathrm{mg} / \mathrm{dl})$ & $2.62 \pm 1.9$ & $2.4 \pm 1.51$ & $160(\mathrm{MW})$ \\
\hline Albumin $(\mathrm{g} / \mathrm{dl})$ & $2.25 \pm 0.5$ & $2.6 \pm 0.2$ & 0.31 \\
\hline AST $(\mathrm{U} / \mathrm{l})$ & $64.21 \pm 29.02$ & $65.43 \pm 32.8$ & 0.243 \\
\hline ALT $(\mathrm{U} / \mathrm{l})$ & $40.2 \pm 23.2$ & $35.3 \pm 16.8$ & $0.395(\mathrm{MW})$ \\
\hline Child score & $10.1 \pm 0.9$ & $11.5 \pm 1.6$ & 0.324 \\
& & & \\
\hline Child class & $19(31.6 \%)$ & $21(35 \%)$ & 0.513 \\
- Child B & $41(68.4 \%)$ & $39(65 \%)$ & \\
- Child C & & &
\end{tabular}

\begin{tabular}{llll}
\hline INR & $1.68 \pm 0.6$ & $1.59 \pm 0.51$ & 0.59 \\
\hline Potassium $(\mathrm{mmol} / \mathrm{l})$ & $3.5 \pm 0.88$ & $3.65 \pm 0.79$ & 0.492 \\
\hline Sodium $(\mathrm{mmol} / \mathrm{l})$ & $130.82 \pm 3.1$ & $132.9 \pm 2.9$ & $\mathbf{0 . 0 4}(\mathbf{S})$
\end{tabular}

MW=Mann Whitney

Table 2 exhibits effect of rifaximin on incidence rate of multiple variables:

\begin{tabular}{|c|c|c|c|c|c|}
\hline & $\begin{array}{c}\text { Control } \\
\text { group } \\
\text { incidence } \\
\text { ratio } \\
\text { per } 3 \text { months }\end{array}$ & $\begin{array}{l}\text { Rifaximin } \\
\text { group } \\
\text { incidence } \\
\text { ratio } \\
\text { per } 3 \text { months }\end{array}$ & $\begin{array}{l}\text { Rifaximin group } \\
\text { as compared } \\
\text { to control } \\
\text { (incidence rate } \\
\text { ratio) }\end{array}$ & $\begin{array}{c}95 \% \text { CI } \\
\text { of } \\
\text { Incidence } \\
\text { rate ratio }\end{array}$ & $\mathrm{P}$ value \\
\hline AKI & 3.68 & 1.39 & 0.7 & $0.53-0.92$ & $<0.001(\mathrm{HS})$ \\
\hline HRS & 0.62 & 0.071 & 0.21 & $0.06-0.7$ & $<0.001(\mathrm{HS})$ \\
\hline $\begin{array}{l}\text { Hepatic } \\
\text { encephalopathy }\end{array}$ & 0.73 & 0.84 & 1.14 & $0.91-1.29$ & 0.2 \\
\hline Paracentesis & 0.81 & 1.19 & 1.43 & $0.75-2.62$ & 0.24 \\
\hline $\begin{array}{l}\text { Variceal } \\
\text { bleeding }\end{array}$ & 0.17 & 0.07 & 0.48 & $0.09-2.5$ & 0.34 \\
\hline $\begin{array}{l}\text { Spontaneous } \\
\text { bacterial } \\
\text { peritonitis }\end{array}$ & 1.82 & 0.64 & 0.41 & $0.45-0.78$ & $<0.001(\mathrm{HS})$ \\
\hline
\end{tabular}


Table 3 exhibits sequential renal function analysis:

\begin{tabular}{|c|c|c|c|c|c|c|}
\hline \multirow[b]{2}{*}{ Weeks } & \multicolumn{3}{|c|}{ BUN } & \multicolumn{3}{|c|}{ Creatinine } \\
\hline & $\begin{array}{c}\text { Control } \\
\text { group }\end{array}$ & $\begin{array}{l}\text { Rifaximi } \\
\text { n } \\
\text { group }\end{array}$ & $P$ value & $\begin{array}{l}\text { Control } \\
\text { group }\end{array}$ & $\begin{array}{l}\text { Rifaximi } \\
\text { n } \\
\text { group }\end{array}$ & $P$ value \\
\hline 1 & $16.9 \pm 5.3$ & $14.8 \pm 5.4$ & 0.692 & $0.88 \pm 0.26$ & $0.96 \pm 0.17$ & $0.951(\mathrm{MW}$ \\
\hline 4 & $16.7 \pm 8.2$ & $16.6 \pm 5.4$ & 0.01 & $0.98 \pm 0.27$ & $0.95 \pm 0.25$ & $\begin{array}{r}\mathbf{0 . 0 4 9} \\
(\mathrm{MW})\end{array}$ \\
\hline 8 & $19.2 \pm 6.8$ & $17.8 \pm 4.2$ & $\begin{array}{l}\mathbf{0 . 0 0 9} \\
(\mathrm{MW})\end{array}$ & $1.16 \pm 0.12$ & $1.08 \pm 0.11$ & $\begin{array}{c}0.21 \\
(\mathrm{MW})\end{array}$ \\
\hline 12 & $22.92 \pm 6.3$ & $\begin{array}{c}15.38 \pm 4 \\
6\end{array}$ & $\begin{array}{l}0.008 \\
(\mathrm{MW})\end{array}$ & $1.19 \pm 0.2$ & $0.99 \pm 0.18$ & 0.04 \\
\hline $\mathrm{P}$ & 0.008 & 0.169 & - & 0.006 & 0.139 & - \\
\hline $\begin{array}{l}\text { Estimated overall } \\
\text { mean }(95 \% \\
\text { confidence } \\
\text { interval })\end{array}$ & $\begin{array}{l}18.9 \\
(17.34- \\
20.52)\end{array}$ & $\begin{array}{c}16.145 \\
(13.09- \\
19.2)\end{array}$ & - & $\begin{array}{c}1.0525 \\
(0.9425- \\
1.1625)\end{array}$ & $\begin{array}{c}0.995 \\
(0.885- \\
1.105)\end{array}$ & - \\
\hline
\end{tabular}

$\mathrm{P}$

0.029

0.038

MW=Mann Whitney

\section{DISCUSSION}

Cirrhotic patients are susceptible to bacterial overgrowth, intestinal dysmotility, and increased bacteria translocation [6]. Bacterial infections are considered one of most important precipitating factors in development of HRS and AKI. The most serious bacterial infection is (SBP). The most common cause of SBP is E.coli which is derived from the gut together with bacterial overgrowth. So intestinal decontamination is very important in preventing HRS type II and AKI in cirrhotic patients. Specific intestinal decontamination with norfloxacin in alcoholic cirrhotic patients improved vascular tone by relatively inverting the chronic portal and systemic vasodilation present in alcoholic cirrhotic [7]. Likewise, Fernandez et al. revealed that norfloxacin diminished the occurrence of spontaneous bacterial peritonitis (SBP) and postponed the onset of HRS type II in 35 patients out of 68 patients with advanced cirrhosis [8].

Many antibiotics are used in gut decontamination for treatment of hepatic encephalopathy and prevention of SBP. One of the most important of these antibiotics is rifaximin which had lowest side effect and high selectivity for gut pathogen and high gut concentration because of poorly absorbed. Rifaximin was more beneficial than norfloxacin in prevention of SBP [9]. It was utilized to treat hepatic encephalopathy [10], and decrease hospital admission [3]. Rifaximin was beneficial for the primary prevention of SBP whether used alone [11] or in addition to norfloxacin [12]. In patients with alcoholic hepatitis, prognosis as well as the renal functions and hemodynamic were enhanced with rifaximin therapy [4], [5].

Cirrhotic patients with bacterial translocation and endotoxemia manifest hemodynamic disturbance, decreased systemic vascular resistance, higher cardiac output, and hypotension. This overgrowth of bacteria is accompanied by increased levels of endotoxins and cytokines such as interleukin6 (IL-6) and tumor necrosis factor- $\alpha$ (TNF- $\alpha$ ) which in turn is accompanied by an increased risk of developing renal injury and death [13]. A study done by Kalambokis et al. showed that rifaximin decreased circulating levels of TNF-a and enhanced hemodynamic by an 
increase in systemic vascular resistance and glomerular filtration rate [4]. Also, endotoxins increase portal vascular resistance by the release of endothelin and cyclooxygenase products [13].

Recently, a randomized clinical trial made by Kimer et al. denied the hemodynamic effect of rifaximin. $\mathrm{He}$ assessed the impact of 4 weeks of rifaximin on 36 alcoholic cirrhotic patients. On follow-up, rifaximin had no impact on the systemic and portal vascular resistance, glomerular filtration rate, blood pressure, and cardiac output. It only decreased bacterial translocation as measured by lipopolysaccharide-binding protein [14], but a small number of patients and alcohol as the only cause of cirrhosis made this result doubtful.

In our study, rifaximin group of patients had more stable renal functions with fewer episodes of renal dysfunction over the 12week treatment period compared with the control group. Also, they had the lowest incidence of HRS type II and AKI. This is mainly due to the effect of rifaximin in decreasing bacterial translocation and the incidence of SBP. Also due to its role in increasing in systemic vascular resistance and glomerular filtration rate and decreasing portal vascular resistance by its inhibitory effect of bacterial overgrowth and cytokines release[4, 13].This was in agreement with Dong et al. who investigated the long-term impact of rifaximin on the renal functions in cirrhotic patients and he found that patients used rifaximin for at least 90 days had lower frequency of AKI, HRS type II, and the demand for renal replacement therapy. Most patients in his study were mainly alcoholic, but in our study, all patients were hepatitis c virus (HCV) cirrhotic patients [15]. There were no significant differences regarding encephalopathy, need for paracentesis and variceal bleeding,

In our study the main limitation is the small number of patients and the cause of cirrhosis in all patients was $\mathrm{HCV}$. Conducting future studies examining the role of rifaximin in decreasing incidence of hepatorenal syndrome type II and acute kidney injury in different liver disease is highly recommended. Finally, the association between the use of rifaximin with incidence of hepatorenal syndrome type II and acute kidney injury in cirrhotic patients should be addressed through prospective studies.

Conclusion

Use of rifaximin is associated with decreased incidence of hepatorenal syndrome type II and acute kidney injury in Egyptian HCV cirrhotic patients.

Disclosure of potential conflicts of interest: The authors report no conflicts of interest.

\section{Contributions:}

AE generated the research idea.

AA formatted the design of the study.

All authors shared in taking patients history, performing the clinical examination, following up of patients.

NG analyzed and interpreted the patient data. All authors shared in writing the manuscript. All authors read and approved the final manuscript.

\section{REFERENCES}

1. Low G, Alexander GJ, Lomas DJ. Hepatorenal syndrome: aetiology, diagnosis, and treatment. Gastroenterol Res Pract, 2015; 207012.

2. Angeli P, Gines P, Wong F, Bernardi M, Boyer TD, Gerbes A, et al.Diagnosis and management of acute kidney injury in patients with cirrhosis: revised consensus recommendations of the International Club of Ascites. J Hepatol, 2015; 62: 968-74.

3. Mullen KD, Sanyal AJ, Bass NM, Poordad FF, Sheikh MY, Frederick RT, et al. Rifaximin is safe and well tolerated for long-term maintenance of remission from overt hepatic encephalopathy. ClinGastroenterolHepatol, 2014; 12: 1390-7.

4. Kalambokis GN, Mouzaki A, Rodi M, Pappas K, Fotopoulos A, Xourgia X, et al. Rifaximin improves systemic hemodynamics and renal function in patients with alcohol-related cirrhosis and ascites. ClinGastroenterolHepatol, 2012; 10: 815-8.

5. Vlachogiannakos J, Viazis N, Vasianopoulou P, Vafiadis I, Karamanolis DG, Ladas SD. Longterm administration of rifaximin improves the prognosis of patients with decompensated alcoholic cirrhosis. J GastroenterolHepatol, 2013; 28: 450-5.

6. Thalheimer U, Triantos CK, Samonakis DN, Patch D, BurroughsAK. Infection, coagulation, 
and variceal bleeding in cirrhosis. Gut, 2005; 54: 556-563.

7. Rasaratnam B, Kaye D, Jennings G, Dudley F, Chin-Dusting JPF. The effect of selective intestinal decontamination on the hyperdynamic circulatory state in cirrhosis: a randomized trial. Ann Intern Med, 2003; 139: 186-193.

8. Fernández J, Navasa M, Planas R, Montoliu S, Monfort D, Soriano G, et al. Primary prophylaxis of spontaneous bacterial peritonitis delays hepatorenal syndrome and improves survival in cirrhosis. Gastroenterol, 2007; 133: 818-824.

9. Elfert A, Abo Ali L, Soliman S, Ibrahim S, Abd-Elsalam S. Randomized controlled trial of rifaximin versus norfloxacin for secondary prophylaxis of spontaneous bacterial peritonitis. Eur J GastroenterolHepatol, 2016; 28: 1450-1454.

10. Khokhar N, Qureshi MO, Ahmad S, Ahmad A, Khan HH, Shafqat F, et al. Comparison of once a day rifaximin to twice a day dosage in the prevention of recurrence of hepatic encephalopathy in patients with chronic liver disease. J GastroenterolHepatol, 2015; 30: 1420-1422.

11. Hanouneh MA, Hanouneh IA, Hashash JG, Law R, Esfeh JM, Lopez R, et al. The role of rifaximin in the primary prophylaxis of spontaneous bacterial peritonitis in patients with liver cirrhosis. J ClinGastroenterol, 2012; 46: 709-715.

12. Assem M, Elsabaawy M, Abdelrashed M, Elemam S, Khodeer S, Hamed $\mathrm{W}$, et al. Efficacy and safety of alternating norfloxacin and rifaximin as primary prophylaxis for spontaneous bacterial peritonitis in cirrhotic ascites: a prospective randomized open-label comparative multicenter study. HepatolInt, 2016; 10: 377-385.

13. Wadei HM, Mai ML, Ahsan N, Gonwa TA. Hepatorenal syndrome: pathophysiology and management. Clin J Am SocNephrol, 2006; 1: 1066-1079.

14. Kimer N, Pedersen JS, Busk TM, Gluud LL, Hobolth L, Krag A, et al. Rifaximin has no effect on hemodynamics in decompensated cirrhosis: a randomized, double-blind, placebocontrolled trial. Hepatol, 2017; 65: 592-603.

15. Dong T, Aronsohn A, Gautham Reddy K, Te HS. Rifaximin decreases the incidence and severity of acute kidney injury and hepatorenal syndrome in cirrhosis. Dig Dis Sci, 2016; 61: 3621-3626.

\section{How to Cite}

El-Gebaly, A., Ghanem, N., Abdelmoaty, A. Effect of rifaximin in the prevention of acute kidney injury and hepatorenal syndrome type II in Egyptian cirrhotic patients. Zagazig University Medical Journal, 2021; (560566): -. doi: 10.21608/zumj.2021.57979.2083 